\title{
The Analysis of Actual and Expected Inflation in Turkey
}

\author{
Selçuk Alp ${ }^{1, *}$, Elçin Aykaç Alp ${ }^{2}$ \\ ${ }^{1}$ Department of Industrial Engineering, Yildiz Technical University, Turkey \\ ${ }^{2}$ Department of Economics, Istanbul Commerce University, Turkey
}

Copyright $\mathrm{C} 2017$ by authors, all rights reserved. Authors agree that this article remains permanently open access under the terms of the Creative Commons Attribution License 4.0 International License

\begin{abstract}
The main objective of the Central Bank is to maintain price stability. Policy objectives set out in this direction and policy instruments used for this purpose can be varied. Inflation expectations are considered to be one of the most important policy instruments used today. Especially in the implementation of the inflation targeting regime, emerges a phenomenon to be studied in as the monitoring of inflation expectations, management, ensuring compliance with set targets. In case of inflation targeting regime implementation; the management, monitoring and meeting targets emerges as a phenomenon to be studied. Since 2002 Central Bank of the Republic of Turkey has been monitoring and publishing its expectations for inflation. Those inflation expectations are followed and published regularly. The publication and monitoring has been through the implementation expectations surveys of the Central Bank of the Republic of Turkey. This paper examines the consistency of the inflation rates with the inflation expectations since 2003. Comparative analysis of the consistency has been analysed by the expectations data for the "current month", "one month ahead", "two months ahead" and "twelve months ahead" and disclosed for the actual inflation rate and inflation expectations. Markov chains analysis was used to examine this adjustment. The resulting long-term equilibrium (steady state) levels were compared to the expected realization via probabilities.
\end{abstract}

Keywords Markov Chain, Expected Inflation, Central Bank Policy

\section{Introduction}

Numerous studies is available that examined the effectiveness of economic policies for ensuring price stability which is one of the main objectives of Central Banks. In a significant portion of those work; inflation expectations and its importance is being questioned. From this point in the literature there are studies on the analysis of macroeconomic variables which affect inflation expectations.

Another area of study cited by inflation expectations are expectations management and studies that questioned the success of expectation management and credibility of the central bank policy. Those types of studies are focused on expectations and especially investigates weather the economics actors decisions are consistent with rational expectation hypothesis. Some of those studies put forth that the expectations consistency and rationality is subject to the policy and the tools used for this policies. Some of the recent studies on this topic are given below.

Bilgili [1] has tested the hypothesis of rational expectations and showed that the presence of rationality rejected. The period of 2000-2005 is researched by Barlas-Özer and Mutluer [2] and the rationality of the inflation expectation has been tested by utilizing the Bias test and Multinomial Logistic regression model. Consequently it has been reached that the following expectations are irrational.

Başkaya et al. [3] study the period in 2002-2005 has examined the success in managing expectations of the CBRT (Central Bank of Republic of Turkey) and showed that the real sector attaches greater importance to the past periods inflation rates than the financial sector. They showed that financial sector ascribed greater importance to more volatile variables in short and medium-term.

Başkaya et al. [4] study found that inflation expectations are affected by various macroeconomic variables like previous terms inflation rates, exchange rate, industrial production index and the annual change in oil prices.

Abdioğlu and Yılmaz [5] studied this subject on Turkey for the period 2005-2012 and analyzed expected inflation, interest rate and exchange rate variables are tested for the accuracy of rational expectations hypothesis with autocorrelation, orthogonality, and efficiency tests and concluded that by the economic actors irrational behavior.

The success of expectations of inflation, as can be seen from the literature, according to vary to the success of economic policy applied, the independence of the central bank and according to the economic political situation in the country. Similarly, the success of policies in force is related to the proper management of inflation expectations and guidance.

During the period of 2006-2012, Başkaya et al. [6] 
researched the sensitivity of the progression of inflation expectancies towards the targets, official predictions and realizations of the inflation. The research yielded the result that the inflation expectancies could be explained by utilizing the official predictions, targets of inflation and realization of inflation. Another result of the study is that tight monetary policies reduce the sensitivity of inflation expectancies.

In this study we examined the compatibility of the inflation rates with the inflation expectations since 2003 . Comparative analysis of this compatibility, the expectations of the "current month", "one month ahead", "two months ahead " and "twelve months ahead" has been subjected to analysis of data individually and disclosed for the actual inflation rate and inflation expectations. Markov Chain analysis has been employed. With the help of the acquired long term steady state probabilities, the realization levels of the expected inflation are compared.

\section{Empirical Methodology}

Markov Analysis is a method which uses the probabilities at hand to calculate the probabilities in the future [7].

To set the models which symbolize the Markov Process, the system at hand must have different states which it can achieve and the probabilities of the system of changing from one of these states to another must be known. A change of state depends only on the previous state, not on any older state. Due to this fact, the system does not need to know any older state than the previous state. This rule is named Markov Property. A Markov Chain is a Markov Process which satisfies Markov Property and which has discrete state space and discrete parameter space.

A stochastic process $X=\left\{X_{n}: \mathrm{n} \geq 0\right\}$ on a countable set $\mathrm{S}$ is a Markov Chain.

$$
\begin{gathered}
P\left\{X_{n+1}=j \mid X_{0}, \ldots, X_{n}\right\}=P\left\{X_{n+1}=j \mid X_{n}\right\} \\
P\left\{X_{n+1}=j \mid X_{n}=i\right\}=p_{i j} \\
i, j \in S \\
n \geq 0
\end{gathered}
$$

This is the probability that the Markov chain jumps from state $i$ to state $j[8]$.

$$
\begin{array}{ll}
0 \leq p_{i j} \leq 1, & i, j \geq 0 \\
\sum_{j=0}^{\infty} p_{i j}=1 & i=0,1,2, \ldots
\end{array}
$$

$p_{i j}$ is called Markov Transition Matrix and is the matrix which is consist of the probabilities of change. The notation is $P=\left[p_{i j}\right]$ [9].

When the State Space is finite like $S=\{0,1,2, \ldots, N\}$, the
One Change Probability Matrix for the Markov Chain will be like:

$$
P=\left[p_{i j}\right]=\begin{gathered}
0 \\
0 \\
\vdots \\
N
\end{gathered}\left[\begin{array}{cccc}
p_{00} & p_{01} & \cdots & p_{0 N} \\
p_{10} & p_{11} & \cdots & p_{1 N} \\
\vdots & \vdots & \vdots & \vdots \\
p_{N 0} & p_{N 1} & \cdots & p_{N N}
\end{array}\right]
$$

The probability for a process for being in the state (j) at time $(t+1)$ when the process is in the state (i) at time ( $t)$ is noted by (pij). When the process is in state (i) at time (m) the probability for this process to be in state (j) in (n) steps is noted by $\left(P_{i j}^{n}\right)$ and is called n-step transition probabilities. For $(\mathrm{n}=0,1,2, \ldots) \mathrm{n}$-step transition probability is shown by:

$$
P_{i j}^{n}=P\left(X_{n+m}=j \mid X_{m}=i\right)=P\left(X_{n}=j \mid X_{0}=i\right) \quad i, j \in S
$$

To find the n-step transition probabilities shown above, the Chapman-Kolmogorov Equation $P^{(n)}=P^{(n-1)} \times P=P^{n}$ is employed. According to this equation, n-step transition probabilities are calculated by multiplying the matrix $(\mathrm{P}) \mathrm{n}$ times by itself.

The process in a Markov Chain reaches the state of equilibrium state or the steady state after long time. In this case, noteworthy statements can be made about the future of the process [10].

\section{Data and Empirical Results}

\subsection{Data}

In this study the monthly declared values of inflation expectations by CBRT for the period of February 2003 to October 2015 are used. The variables subject to the analysis are, the CPI expectations for the current month, the highest CPI expectations for the current month, the lowest CPI expectations for the current month, the CPI expectations for the next month, the highest CPI expectations for the next month, the lowest CPI expectations for the next month, the CPI expectations for 12 months ahead, the highest CPI expectations for 12 months ahead, the lowest CPI expectations for 12 months ahead.

In the second part of the analysis the difference between the highest and lowest values of the expectancies are taken and a difference data set for each period have been made.

\subsection{Empirical Results}

In this study, the relation between the monthly declared questionnaire results about the inflation expectations for the current moth by CBRT (Central Bank of Turkey) and the real inflation values is examined. In the analysis Markov Chain Method with regard to just the periods at time $t$ and $t+1$ is employed and two different cases are examined.

In the first case we investigated the relationship if the inflation expectations increase or decrease of the minimum 
and maximum values in period $t$ affected $t+1$ period of the relationship between actual and realized value of inflation increased or have decreased the value of inflation.

Long run steady state probabilities calculated from Markov Chain analysis are given in Table 1.

Examples for the long run steady state probability estimation results which are estimated for current month information are given below;

When the maximum value of the expected inflation decreases according to the previous month, inflation also decreases for the $63.77 \%[0.6377=(0.2461+0.0675) /$
$(0.2461+0.0660+0.0675+0.1121)]$ of the observed values.

When the maximum value of the expected inflation decreases according to the previous month, inflation increases for the $36.22 \%[0.3622=(0.0660+0.1121) /$ $(0.2461+0.0660+0.0675+0.1121)]$ of the observed values.

The probabilities for current month, one month ahead, two month ahead and twelve month ahead realization probabilities according to increasing and decreasing values of maximum and minimum values of expectations of previous term are reported in Table 2 .

Table 1. Long Run Steady State Probabilities

\begin{tabular}{|c|c|c|c|c|}
\hline State & Current Month & One Month Ahead & Two Month Ahead & Twelve Month Ahead \\
\hline Max-Min-I- & 0.2461 & 0.1055 & 0.2270 & 0.1002 \\
\hline Max-Min-I+ & 0.0660 & 0.1532 & 0.0890 & 0.0847 \\
\hline Max-Min+I- & 0.0675 & 0.1172 & 0.0889 & 0.1413 \\
\hline Max-Min+I+ & 0.1121 & 0.1190 & 0.1065 & 0.1555 \\
\hline Max+Min-I- & 0.0595 & 0.0803 & 0.0648 & 0.0767 \\
\hline Max+Min-I+ & 0.0792 & 0.0808 & 0.0881 & 0.1465 \\
\hline Max+Min+I- & 0.0861 & 0.1588 & 0.0782 & 0.1418 \\
\hline Max+Min+I+ & 0.2835 & 0.1832 & 0.2574 & 0.1533 \\
\hline
\end{tabular}

Table 2. Expected Values Realization Probabilities for Maximum and Minimum Values of Expectations

\begin{tabular}{|c|c|c|c|}
\hline \multirow{3}{*}{ Term } & Expectation & \multicolumn{2}{|c|}{ Realization } \\
\cline { 2 - 4 } & & Decrease & Increase \\
\hline \multirow{3}{*}{ Current Month } & Decrease in maximum value & 63.77 & 36.22 \\
\cline { 2 - 4 } & Increase in maximum value & 28.64 & 71.35 \\
\cline { 2 - 4 } & Decrease in minimum value & 67.79 & 32.20 \\
\hline \multirow{3}{*}{ One Month Ahead } & Increase in minimum value & 27.96 & 52.03 \\
\cline { 2 - 4 } & Decrease in maximum value & 44.99 & 55.01 \\
\cline { 2 - 4 } & Increase in maximum value & 47.52 & 52.47 \\
\cline { 2 - 4 } & Decrease in minimum value & 44.25 & 52.26 \\
\hline \multirow{3}{*}{ Two Month Ahead } & Increase in minimum value & 47.73 & 38.22 \\
\cline { 2 - 4 } & Decrease in maximum value & 61.77 & 70.72 \\
\cline { 2 - 4 } & Increase in maximum value & 29.27 & 37.76 \\
\cline { 2 - 4 } & Decrease in minimum value & 62.23 & 68.53 \\
\hline \multirow{3}{*}{ Twelve Month Ahead } & Increase in minimum value & 31.46 & 49.86 \\
\cline { 2 - 4 } & Decrease in maximum value & 50.13 & 57.84 \\
\cline { 2 - 4 } & Increase in maximum value & 42.15 & 56.65 \\
\cline { 2 - 4 } & Decrease in minimum value & 43.34 & 52.17 \\
\hline
\end{tabular}


The results reported in Table 2 can be interpreted as below;

When the maximum value of the expected inflation decreases according to the previous month, for the $63.77 \%$ of the observed values, inflation is also decreases for the present month. When the maximum value of the expected inflation increases in comparison with the previous month, the inflation also increases for the $71.35 \%$ of the observed values.

The period which was subject to the analysis was a period in which monetary policies were applied in order to decrease the inflation. Therefore, the declarations and precautions were aimed towards reducing the inflation. In this situation, if the people whose inflation expectations realized at maximum level are categorized as "pessimists" and if the people whose inflation expectations realized at minimum level are categorized as "optimists", it has been observed that the probability of pessimists expecting the current month's inflation rate increase by utilizing the previous month's rate increase is higher.

It is calculated that for the people whose inflation expectations is at the minimum level for the current month and expect an increase in comparison with the previous period, the probability of being right is $72.03 \%$, whereas for the people who expect a decrease, the probability of being right is $67.79 \%$.

The analysis which was taken into account for one month ahead expectations have shown that there was no significant difference between the calculated probabilities.

The expectations for the following two months were analyzed from April 2006 to 2015. It should be stated that comparing the results would not be accurate with other results since there is difference between other periods analyzed. The new period which is being analyzed is a period in which a new currency policy (explicit inflation targeting) and a new president of the central bank are important factors. Therefore, it has been found acceptable that the results obtained in this period should be evaluated separately.

When the expectations for the following two months are analyzed, the probability of the realization of expectations for people whose expectations occurred at maximum level and foresee an increase is calculated as $70.72 \%$, whereas for people who expect a decrease, the probability of realization is calculated as $61.77 \%$.

For people whose inflation expectations are at minimum level but expect an increase, the probability of realization is observed as $68.53 \%$, whereas for people who expect a decrease, the probability of realization is observed as $62.23 \%$.

When the expectations for the following twelve months are analyzed, the probability of realization for people whose inflation expectations realized at maximum level and foresee an increase, is observed as $57.84 \%$, whereas the probability of realization for people who expect a decrease is observed as $50.13 \%$. For people whose expectations is at minimum level but expect an increase, the probability of realization is observed as $52.17 \%$, whereas for people who expect a decrease, the probability of realization is observed as $43.34 \%$.

In second case we investigated the relationship if the difference between maximum and minimum values of inflation expectations increase or decrease in period $t$ affected $t+1$ period of the relationship between actual and realized value of inflation increased or have decreased the value of inflation.

Table 3. Expected Values Realization Probabilities for Differenced Maximum and Minimum Values of Expectation

\begin{tabular}{|c|c|c|c|}
\hline \multirow{2}{*}{ Term } & \multirow{2}{*}{$\begin{array}{c}\text { Expectation } \\
\text { (Difference between } \\
\text { maximum and } \\
\text { minimum value) }\end{array}$} & \multicolumn{2}{|c|}{ Realization } \\
\cline { 2 - 4 } & $\begin{array}{c}\text { Decrease } \\
\text { Current Month }\end{array}$ & 49.97 & 50.02 \\
\cline { 2 - 4 } & Increase & 41.27 & 58.72 \\
\hline \multirow{2}{*}{$\begin{array}{c}\text { One Month } \\
\text { Ahead }\end{array}$} & Decrease & 48.51 & 51.74 \\
\cline { 2 - 4 } & Increase & 42.47 & 57.52 \\
\hline \multirow{2}{*}{$\begin{array}{c}\text { Two Month } \\
\text { Ahead }\end{array}$} & Decrease & 51.93 & 48.06 \\
\hline \multirow{2}{*}{$\begin{array}{c}\text { Twelve Month } \\
\text { Ahead }\end{array}$} & Increase & 38.50 & 61.49 \\
\cline { 2 - 4 } & Decrease & 51.70 & 48.29 \\
\hline
\end{tabular}

At Table 3, it is supposed that the expansion of the bandwidth between the maximum and minimum level values to uncertainty or unclearity during the formation of an expectation, whereas the narrowing of the bandwidth points to the decrease of uncertainty.

When the current month expectations and inflation realizations are analyzed, in case of the narrowing of the bandwidth, the probability of an increase in the inflation is calculated as $50.02 \%$, whereas in case of an expansion of the bandwidth, the probability of an increase in the inflation is calculated as $58.72 \%$.

When the expectations for the following month are analyzed in case of the narrowing of the bandwidth, the probability of an increase in the inflation is calculated as $51.74 \%$, whereas in case of an expansion of the bandwidth, the probability of an increase in the inflation is calculated as $57.52 \%$.

When the expectations for the following two month analyzed, in case of the narrowing of the bandwidth, the probability of an increase in the inflation is calculated as $48.06 \%$, whereas in case of an expansion of the band with, the probability of an increase in the inflation is calculated as $61.49 \%$.

When the expectations for the following twelve month analyzed, in case of the narrowing of the bandwidth, the probability of an increase in inflation is calculated as $48.29 \%$, whereas in case of an expansion of the band with, the probability of an increase in the inflation is calculated as $57.06 \%$. 


\section{Conclusions}

This paper examines the consistency of inflation target with inflation expectations since the 2003. For the comparative analysis of the consistency we used the expectations of the "current month ", "one month ahead ", "two months ahead" and " twelve months ahead" announced data separately. Inflation expectations and actual values were subjected to analysis. Contrary to usual behavior with the calculation with the usage of forecast values described, the relationship between the maximum and minimum values occur with the calculated values in the period were examined.

Investigated period is a period of which monetary policies were applied in order to decrease the inflation in an active way to reduce inflation and the declarations and precautions were used towards this goal. The findings were compared in the case of the inflation expectations of those held at the maximum level accepted as pessimist and those who held to a minimum level accepted as optimistic.

The findings obtained by these analyses are generally likely to result in minimum terms of realization of expectations is higher than the probability of the realization of the expectations established at the maximum level. Therefore realization of the expectations of these actors is more likely to occur with optimistic expectations. In addition, when both the maximum and minimum values analyzed the probability of an accurate estimation of the actual value will be higher.

Second part of the study encloses the uncertainty and unclearity of signals by calculating the range for the maximum and minimum levels of inflation expectations. Higher bandwidth signs an uncertainty in case of lower bandwidth signs a decrease in uncertainty of signals. Using bandwidth values helps to understand the relationship between inflation expectations and realizations for the periods of different uncertainty levels.

This analysis showed that the probability of increase in inflation in case of the expansion of the bandwidth (signs uncertainty) is higher than the probability of a decrease in inflation.

\section{REFERENCES}

[1] Bilgili, F. (2001). The Unbiasedness and Efficiency Tests of the Rational Expectations Hypothesis. MPRA Working Paper, 24114: 1-22.

[2] Barlas-Özer, Y., Mutluer, D. (2005). Inflation Expectations in Turkey: Statistical Evidence from the Business Tendency Survey. Central Bank Review, 5(2): 73-97.

[3] Başkaya, Y. S., Kara, H., Mutluer, D. (2008). Expectations, Communication, and Monetary Policy in Turkey. CBRT Working Paper, No: 08/01.

[4] Başkaya, Y. S., Gülşen, E., Orak, M. (2010). 2008 Hedef Revizyonu Öncesi ve Sonrasında Enflasyon Beklentileri. TCMB Ekonomi Notu, No: 2010-1.

[5] Abdioğlu, Z., Yılmaz, S. (2013). Rasyonel Beklentiler Hipotezinin Testi: Enflasyon, Faiz ve Kur. Çukurova Universitesi IIBF Dergisi 17 (1), 17-35.

[6] Başkaya, Y.S., Gülşen, E., Kara, A. H. (2012). Inflation Expectations and Central Bank Communication in Turkey. Central Bank Review, 12(2), 1-10.

[7] Timor, M. (2010). Yöneylem Araştırması, Istanbul, Turkey: Türkmen Kitabevi.

[8] Serfozo, R. (2009). Basic of Applied Stochastic Processes, Probability and its Applications, Springer-Verlag, Berlin Heidelberg.

[9] Chung, K. L., Walsh J. B. (2005). Markov Processes, Brownian Motion, and Time Symmetry, (2nd ed.) United States of America: Springer Science Business Media Inc.

[10] Levin, R.I., Kirkpatrick, C. A., Rubin, D.S. (1982). Quantitative Approaches to Management (5th ed.). Tokyo, Japan: Mc-Graw-Hill. 